\title{
A TECHNIQUE FOR THE DETECTION OF MINIMAL NUMBERS OF MALARIA PARASITES; ITS APPLICATION IN THE DETECTION OF SUPPRESSED VIVAX MALARIA 1, 2,
}

\author{
By ROBERT W. BERLINER, THOMAS J. KENNEDY, JR.,4 \\ AND FREDERICK S. BIGELOW 4 \\ (From the Department of Medicine, New York University College of Medicine, and the \\ Research Service, Third [New York University] Medical Division, \\ Goldwater Memorial Hospital, New York City)
}

(Received for publication March 12, 1947)

It has been demonstrated, by the subinoculation of large volumes of blood, that malaria parasites are present in the peripheral circulation of individuals who have been bitten by infected mosquitoes but whose disease is suppressed with adequate treatment (1). Since each examination by this procedure requires the use of an additional volunteer subject, a substitute method which yields the same information without necessitating a corresponding utilization of recipients should be highly desirable.

Whereas not less than 10 malaria parasites per $\mathrm{mm} .^{3}$ or 10,000 per $\mathrm{cm}^{3}$ of blood are required to be uniformly detectable by the usual thick smear examination, the method of Ferrebee and Geiman (2) for the preparation of concentrates of parasitized red blood cells is applicable, with slight modification, to the demonstration of Plasmodium vivax at parasite densities far below those required for detection by the routine laboratory method. The modified concentration technique permits the demonstration of parasites when they are present in concentrations of less than 100 per cm..$^{8}$ of blood.

1 The work described in this paper was done under a contract, recommended by the Committee on Medical Research, between the Office of Scientific Research and Development and New York University.

$2 \mathrm{~A}$ portion of this work was presented at the meetings of the Federation of American Societies for Experimental Biology, March 11-15, 1946, Federation Proc., 1946, 5, 165.

3 The authors express their thanks to the Malaria Study Section of the National Institute of Health for editorial assistance and for arrangements in regard to the publication of this paper. They are also grateful to the Abbott Laboratories, E. I. du Pont de Nemours and Company, Inc., E. R. Squibb and Sons, Eli Lilly and Company, Sharp and Dohme, and Wyeth, Inc., for contributing toward the publication costs.

4 Captain, MC, AUS.
The present report deals with the application of a concentration procedure to the detection of parasites in patients with suppressed vivax malaria.

The parasite concentration procedure is essentially that of Ferrebee and Geiman (2) modified by a preliminary removal of white blood cells. This additional step is essential since otherwise the white blood cells present in whole blood are concentrated along with the parasitized erythrocytes and the white blood cells may completely obscure the parasites in the final smear.

\section{METHODS AND MATERIAL}

Five to $15 \mathrm{ml}$. of venous blood are drawn into a syringe containing an amount of heparin sufficient to prevent clotting. The blood is transferred to a centrifuge tube and spun for 20 minutes at 2000 r.p.m. The plasma layer is removed, avoiding any disturbance of the buffy coat. The white cells are then aspirated off as completely as possible. The plasma which was removed is then poured back into the tube and the red cells and plasma gently mixed. The reconstituted blood is carefully layered over an equal volume of bovine albumin solution ${ }^{8,6}$ in a suitable centrifuge tube. The albumin is prepared by dilution 7 of four parts of the 30 per cent

5 The bovine albumin solution used was kindly provided by Dr. Lesh, medical director of the Armour Laboratories, Chicago, Illinois.

- The stock albumin solution should be kept sterile, since yeast cells and bacteria may completely dominate smears prepared with contaminated solutions.

7 There is some variation in the dilution of 30 per cent bovine albumin required for best results. This is best assayed for each lot of albumin by making a series of dilutions varying about an average of four parts of albumin to one part of saline and testing them against samples of parasitized blood. Normal blood may also be used for this purpose. In this case, the dilution to be used is selected as the one which, in the final step of the concentration technique, yields a fine layer, of red cells just covering the bottom of the centrifuge tube. 
bovine albumin solution as furnished, with one part of normal saline solution. The tube is centrifuged at 1000 r.p.m. for five minutes; the speed is then increased to 2500 r.p.m. and continued for 15 minutes. At the end of this time the material has formed three layers. The blood plasma which constitutes the uppermost layer is removed and discarded. The deepest layer is formed by the normal non-parasitized red blood cells which have passed through the middle albumin layer. The latter, which should be a clear yellow or at most slightly tinged with pink, contains the parasitized red blood cells which, because of their diminished density and the relatively high viscosity of the albumin solution, have been left behind. The albumin layer is removed and mixed with two to three volumes of isotonic saline solution in a conical centrifuge tube. The latter is centrifuged at 2500 r.p.m. for five minutes, driving the contained red cells to the bottom where they usually form a layer just sufficient to cover the bottom of the tube. The saline-albumin mixture is carefully aspirated off. The fluid which runs down the sides of the tube is sufficient to suspend the cells which may be taken up in a fine capillary pipette and transferred to a clean microscope slide where the drop is spread to form a thick blood smear of somewhat less than the usual density. When completely dried the smear is stained with Giemsa stain using the technique usually applied to thick blood smears. The parasites do not differ, in their microscopic appearance, from those seen in thick smears prepared without the preliminary concentration.

The individuals utilized in these studies were volunteers 8 who were inoculated, by the bite of Anopheles quadrimaculatus mosquitoes, ${ }^{9}$ with the Chesson strain (3) of $P$. vivax. This strain, originally isolated from a patient who acquired the infection in the Southwest Pacific, is characterized by repeated early relapses occurring at intervals apparently dependent only on the duration of suppressive therapy.

The data on the concentration of vivax parasites are derived from two types of studies. (A) In the first, each individual was inoculated by the bite of infected mosquitoes, all biting being done on a single day and each mosquito being permitted to engorge on the subject bitten. The salivary glands of mosquitoes whose abdomens were found to contain blood were dissected out and examined for the presence of sporozoites. The density of the gland infection was estimated at 0 to $4+$ and the inoculum received by each volunteer is given as the sum of the densities of the infections in the mosquitoes by which he was bitten. Drugs administered to this group were given daily in divided doses throughout the period of therapy. Ordinary thick smears were obtained daily and examined for parasites, beginning on the eighth day

8 The volunteers in these studies were inmates of the United States Disciplinary Barracks, Green. Haven, New York.

- Many of the infected mosquitoes were furnished by Doctors Clay G. Huff and Frederick Coulston, whose assistance is gratefully acknowledged. after biting and continuing until the development of clinical malaria. Concentrations were done on 10 to 15 ml. of venous blood beginning on the seventh or eighth day after inoculation and continuing until at least two successive positive results were obtained. In five instances, subinoculation of blood to a susceptible recipient was performed on the ninth day. The volume of blood transferred by subinoculation was $200 \mathrm{ml}$. in three instances but, because no compatible recipients were available, the other two were limited to $10 \mathrm{ml}$. volumes.

(B) The second type of study was done incidental to the testing of three derivatives of 4-aminoquinoline for their effectiveness as suppressive antimalarials in fieldtype studies with Chesson strain vivax malaria. The results of this experiment are reported elsewhere (4). The concentrations were done merely to confirm the presence of parasites in the circulating blood and no attempt was made to detect parasites at the earliest possible date. The patients in this study were bitten on three occasions at two-day intervals. The volunteers were divided into ten groups of three. Each subject in a group received a different one of the three drugs. Inoculations were carried out by the interrupted feeding method (5), an equal number of mosquitoes biting each of the three subjects first, second, and third. The drugs were administered in single weekly doses of 0.25 gram of the base, given one week before the first day of inoculation, and on the same day of the two succeeding weeks. Daily examinations for parasites were done by routine smear methods. Concentrations were done at a time during the drug suppression when it was expected that positive results would be obtained.

\section{RESULTS}

Preliminary studies with the concentration procedure showed that parasites could be found in the peripheral blood a few hours after the intravenous injection of one million $P$. vivax trophozoites. Blood containing a known number of parasites was diluted serially with normal blood. It was possible to find parasites present in a concentration of 100 per cm..$^{3}$ but not at 10 per $\mathrm{cm}^{3}$. Attempts to concentrate the parasites in patients infected with $P$. malariae were unsuccessful as might be expected from the fact that the parasitized cells are not enlarged. The same is true of cells containing the young ring forms of $P$. falciparum. Some success was attained in concentrating the more mature forms of $P$. falciparum that develop when blood containing the young ring forms is incubated for 24 to 48 hours, by a modification of the method of Bass and Johns $(6,7)$.

The results of the first type (A) of experiment in vivax infections are presented in Table $I$. 
TABLE I

Comparison of concentration with routine smear method in individuals receiving heavy inoculations of

$P$. vivax sporozoites on one occasion

\begin{tabular}{l|l|c|c|c}
\hline \hline Patient & Inoculum* & $\begin{array}{c}\text { Last } \\
\text { negative } \\
\text { concen- } \\
\text { tration }\end{array}$ & $\begin{array}{c}\text { First } \\
\text { positive } \\
\text { concen- } \\
\text { tration }\end{array}$ & $\begin{array}{c}\text { First } \\
\text { thick } \\
\text { smear } \\
\text { positive }\end{array}$ \\
\hline & \multicolumn{2}{|c|}{ days after inoculation } \\
\hline
\end{tabular}

\begin{tabular}{l|l|l|l|l}
\multicolumn{5}{|c}{ No medication } \\
\hline $\mathrm{Mo}$ & 47 & 8 & 9 & 10 \\
$\mathrm{~Pa}$ & 47 & 8 & 9 & 11 \\
$\mathrm{Oo}$ & 35 & 8 & 9 & 10 \\
$\mathrm{Pe}$ & 35 & 8 & 9 & 12 \\
$\mathrm{Na}$ & 32 & 8 & 9 & 12 \\
\hline
\end{tabular}

Quinine, 2 grams daily, day 0 to day 13

\begin{tabular}{|c|c|c|c|c|}
\hline $\mathrm{Om}$ & 68 & 8 & 9 & 22 \\
\hline \multicolumn{5}{|c|}{ SN-7618 (chloroquine), 0.3 gram daily, day 0 to day 11} \\
\hline $\begin{array}{l}\text { Ja } \\
\text { Lo } \\
\text { Le } \\
\text { Gr } \\
\text { Jo }\end{array}$ & $\begin{array}{l}44 \\
36 \\
35 \\
35 \\
29\end{array}$ & $\begin{array}{l}8 \\
8 \\
8 \\
8 \\
8\end{array}$ & $\begin{array}{l}8 \frac{1}{2} \\
8 \frac{1}{2} \\
8 \frac{1}{2} \\
8 \frac{1}{2} \\
8 \frac{1}{2}\end{array}$ & $\begin{array}{l}75 \dagger \\
70 \dagger \\
63 \dagger \\
81 \dagger \\
75 \dagger\end{array}$ \\
\hline
\end{tabular}

* Sum of densities of gland infections in mosquitoes biting each subject.

$\dagger$ Subinoculation positive on day 9 .

Group I consists of five subjects to whom no suppressive drugs were given. Concentrations were done to find the earliest date on which parasites might be demonstrated and to ascertain the interval by which this would precede detection by routine methods. Parasites are detectable by the concentration procedure on the ninth day after inoculation, preceding detection by the usual methods by one to three days. Group II consists of a single individual who received quinine and five who received $\mathrm{SN}-7618$ (chloroquine) in full therapeutic dosage. Parasites were detectable by the concentration technique $81 / 2$ but not eight days after inoculation. In no instance were direct smears of the blood positive during the period of drug administration, or for a considerable time thereafter, the period of negative smears depending on the suppressive drug used.

The results obtained during the field-type suppressive study (B) are presented in Table II. One subject who received $\mathrm{SN}-6911$ is omitted from the table since the tube containing blood for concentration taken on the tenth day was broken during the procedure. In 28 of the remaining 29 volunteers, parasites were demonstrated by the concentration technique during the period of drug suppression. Of these, five had single positive smears by the routine method during the period of suppression and one had a positive smear on two successive days. The one individual whose blood showed no parasites after concentration failed to develop malaria within 63 days after inoculation at which time observations were discontinued.

TABLE II

Comparison of concentration with routine smear method in field-type suppressive experiment

\begin{tabular}{l|c|c|c|c|c|c|c}
\hline & \multicolumn{2}{|c|}{ Inoculum* } & $\begin{array}{c}\text { Last } \\
\text { nega- } \\
\text { tive } \\
\text { concen- } \\
\text { tration }\end{array}$ & $\begin{array}{c}\text { First } \\
\text { posi- } \\
\text { tive } \\
\text { Poncen- } \\
\text { tration }\end{array}$ & \multicolumn{2}{|c|}{$\begin{array}{c}\text { Thick smears } \\
\text { positive }\end{array}$} \\
\cline { 2 - 6 } & Day 0 & Day 2 & Day 4 & $\begin{array}{c}\text { Tran- } \\
\text { sient }\end{array}$ & $\begin{array}{c}\text { Per- } \\
\text { sistent }\end{array}$ \\
\hline & & & & days after first inoculation \\
\hline
\end{tabular}

SN-6911 (sontochin), 0.25 gram on days $-6,0,7,14$

\begin{tabular}{l|r|r|r|r|r|r|r}
\hline $\mathrm{Pa}$ & 21 & 13 & 8 & 9 & 10 & - & 23 \\
$\mathrm{Ni}$ & 21 & 12 & 9 & 9 & 10 & 14 & .24 \\
$\mathrm{Ha}$ & 28 & 16 & 7 & 9 & 10 & 12,13 & 29 \\
$\mathrm{Si}$ & 12 & 15 & 9 & 9 & 10 & 12 & 31 \\
$\mathrm{Al}$ & 10 & 13 & 11 & 14 & 15 & - & 28 \\
$\mathrm{Ni}$ & 14 & 17 & 24 & - & 14 & - & 28 \\
$\mathrm{~Pa}$ & 7 & 15 & 13 & - & 14 & - & 29 \\
$\mathrm{Ma}$ & 15 & 17 & 18 & - & 14 & - & 26 \\
$\mathrm{Br}$ & 8 & 15 & 13 & 15 & - & - & $\dagger$ \\
\hline
\end{tabular}

$\mathrm{SN}-7618$ (chloroquine), 0.25 gram on days $-6,0,7,14$

\begin{tabular}{l|r|r|r|r|r|l|l}
\hline $\mathrm{Sl}$ & 4 & 7 & 30 & 14 & 15 & - & 47 \\
$\mathrm{Ba}$ & 10 & 14 & 18 & - & 14 & - & 51 \\
$\mathrm{Fo}$ & 7 & 17 & 24 & - & 14 & - & 54 \\
$\mathrm{Od}$ & 6 & 15 & 13 & - & 14 & - & 42 \\
$\mathrm{Gl}$ & 16 & 7 & 18 & - & 14 & - & 49 \\
$\mathrm{El}$ & 23 & 7 & 9 & - & 9 & - & 49 \\
$\mathrm{Mi}$ & 16 & 12 & 7 & 9 & 10 & - & 49 \\
$\mathrm{Ta}$ & 19 & 12 & 16 & 9 & 10 & - & 50 \\
$\mathrm{Ad}$ & 13 & 13 & 16 & 9 & 10 & - & 50 \\
$\mathrm{Je}$ & 22 & 11 & 8 & - & 9 & - & 48 \\
\hline
\end{tabular}

$\mathrm{SN}-8137$ (oxychloroquine), 0.25 gram on days $-6,0,7,14$

\begin{tabular}{l|r|r|r|r|r|l|l}
\hline $\mathrm{Ke}$ & 16 & 0 & 8 & 9 & 10 & 12 & 26 \\
$\mathrm{Dr}$ & 20 & 5 & 20 & - & 9 & 12 & 28 \\
$\mathrm{Da}$ & 9 & 14 & 12 & 9 & 10 & 13 & 26 \\
$\mathrm{Co}$ & 18 & 8 & 8 & 9 & 10 & - & 25 \\
$\mathrm{Sm}$ & 19 & 4 & 15 & 9 & 10 & - & 32 \\
$\mathrm{Le}$ & 10 & 10 & 12 & 14 & 15 & - & 28 \\
$\mathrm{Ke}$ & 10 & 20 & 26 & - & 14 & - & 28 \\
$\mathrm{~Pa}$ & 11 & 14 & 22 & - & 14 & - & 29 \\
$\mathrm{Ha}$ & 8 & 13 & 24 & - & 14 & - & 26 \\
$\mathrm{Hi}$ & 12 & 17 & 18 & - & 14 & - & 30 \\
\hline
\end{tabular}

* Sum of densities of gland infections in mosquitoes biting each subject.

$\dagger$ Never developed positive smears. 
It is probable that the inoculation in this patient was unsatisfactory.

\section{DISCUSSION}

Fairley has shown by subinoculation studies (1) that the parasites of $P$. vivax first appear in the circulating blood $81 / 2$ days after the bite of infected mosquitoes, and that the time of appearance is not influenced by suppressive drugs. The present studies confirm this finding and demonstrate that it is possible to detect the parasites in the blood of infected individuals just as readily by a simple concentration procedure. These results, furthermore, indicate that even full therapeutic doses of suppressive drugs do not influence the initial out-pouring of the erythrocytic forms of the parasites.

No direct estimation of the sensitivity of the concentration method relative to that of subinoculation is possible from these data. It seems possible that the subinoculation procedure may be the more sensitive method, but other considerations weigh so heavily in favor of the concentration method that the latter would seem to be the more generally useful. Since, at least in heavily infected individuals, parasites can be readily detected by the concentration technique even in the presence of highly effective suppressive drugs, it does possess sufficient sensitivity for most purposes. The concentration procedure is applicable to repeated and frequent studies in the same individual. Results are available within several hours rather than weeks as in the case of subinoculation. And, most important, the application of the concentration method obviates the need for an additional compatible volunteer for each study performed.

The concentration procedure may have some usefulness in the detection of parasites in individuals with fever, suspected of having malaria, but in whom no parasites can be demonstrated by the usual means. However, since neither $P$. malariae nor the ring forms of $P$. falciparum can be concentrated, the utility of the procedure for this purpose would be limited.

\section{SUMMARY}

A technique for the detection of minimal numbers of $P$. vivax parasites in the circulating blood is described.

Application of the procedure to the detection of parasites in individuals with suppressed malaria is described and discussed.

\section{BIBLIOGRAPHY}

1. Fairley, N. H., et al., Chemotherapeutic suppression and prophylaxis in malaria. An experimental investigation undertaken by research teams in Australia. Tr. Roy. Soc. Trop. Med. \& Hyg., 1945, 38, 311.

2. Ferrebee, J. W., and Geiman, Q. M., A procedure for preparing concentrates of Plasmodium vivax. J. Infect. Dis., 1946, 78, 173.

3. Ehrman, F. C., Ellis, J. M., and Young, M. D., Plasmodium vivax, Chesson strain. Science, 1945, 101, 377.

4. Berliner, R. W., Earle, D. P., Jr., Taggart, J. V., Zubrod, C. G., Welch, W. J., Conan, N. J., Bauman, E., Scudder, S. T., and Shannon, J. A., Studies on the chemotherapy of the human malarias. VI. The physiological disposition, antimalarial activity, and toxicity of several derivatives of 4aminoquinoline. J. Clin. Invest., 1948, 27, Suppl., 98.

5. Coatney, G. R., Cooper, W. C., and Ruhe, D. S., Studies in human malaria. VI. The organization of a program for testing potential antimalarial drugs in prisoner volunteers. Am. J. Hyg., 1948, in press.

6. Bass, C. C., and Johns, F. M., The cultivation of malarial plasmodia (Plasmodium vivax and Plasmodium falciparum) in vitro. J. Exper. Med., 1912, 16, 567.

7. Berliner, R. W., The in vitro assay of suppressive antimalarial activity: $\dot{P}$. falciparum. Federation Proc., 1946, 5, 164 (abstract). 